\title{
العوامل المفسرة لإدراك المستهلك للمخاطرة عند اتخاذ قرار الشراء
}

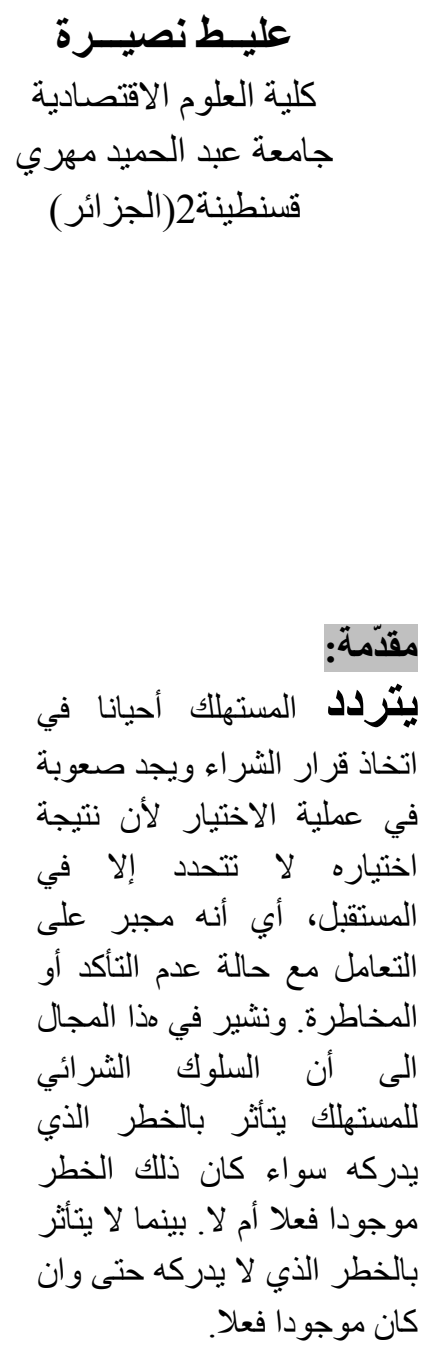

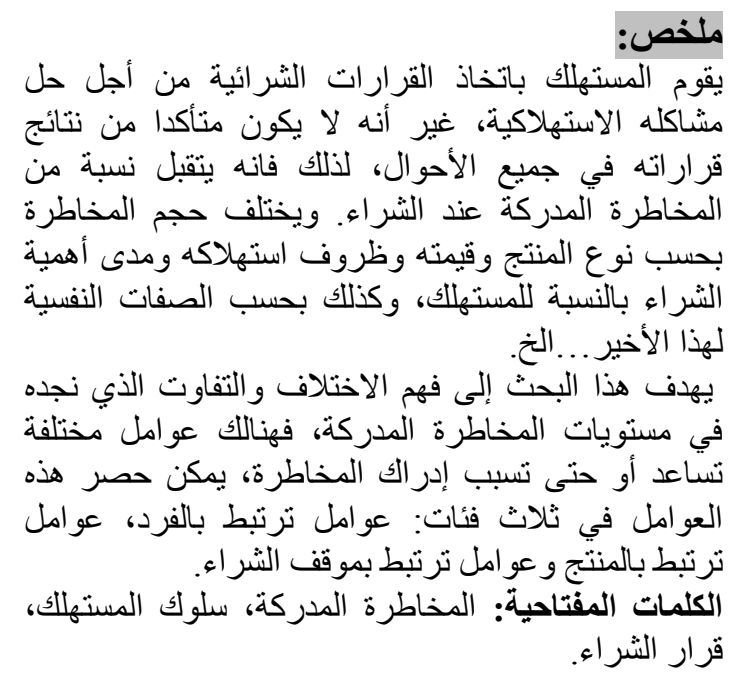

\section{Abstract:}

The consumer makes purchase decisions in order to resolve consumption's issues, but he is usually unsure of his decisions' outcome, so he may bear a part of a perceived risk at purchasing. The level of risk varies according to the type of product and its value, the conditions of consumption and the importance of the purchase, as well as the psychological characteristics of the consumer...

This research aims at comprehending the difference and the variance that we notice in the perceived risk levels, as there are different factors that help, or even cause the perception of risk, These factors can be grouped into three categories: factors associated with the individual, factors linked to the product, and factors associated with the purchase standing.

Key Words: Perceived risk, consumer behavior, purchase decision. 
إن سلوك المستهلك عند الثراء يختلف باختلاف حجم المخاطرة المدركة التي تمثل بأنو اعها المختلفة

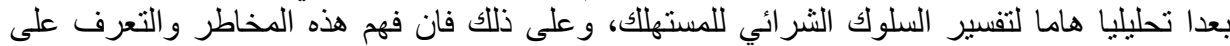

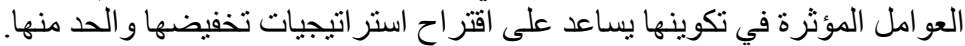

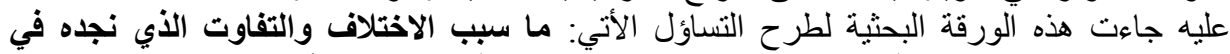

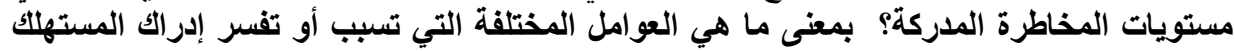

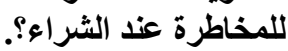
بيسعى البحث إلى تحقيق الأهداف الآتية :

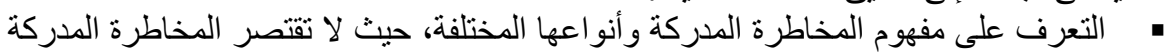

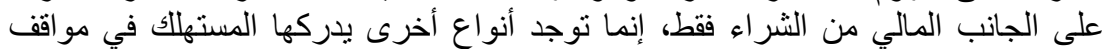

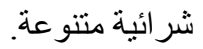
" محاولة توضيح العو امل المختلفة التي تسبب أو تفسر إدر اك المستهلك للمخاطرة عند الثراء.

$$
\begin{aligned}
& \text { اعتمادا على مشكلة الدر اسة و أهدافها تمّ صياغة الفرضيات الآتية: }
\end{aligned}
$$

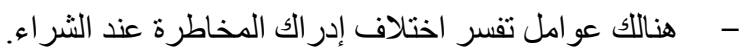

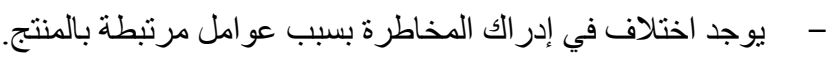

$$
\begin{aligned}
& \text { - - يو جد اختلاف في إدر الك المخاطرة بسبب عو امل مرتبطة بالفرد. }
\end{aligned}
$$

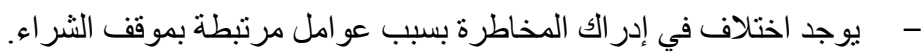

إن طبيعة البحثث الحالي استلزم استخدام منهج البحث الوصفي، حيث تم استخدام أسلوب البحث الوثائقي

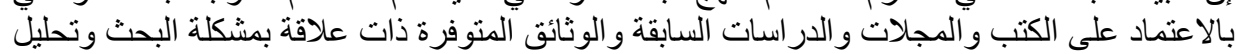

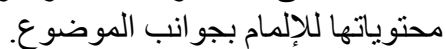

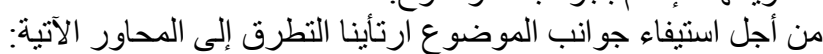

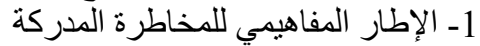

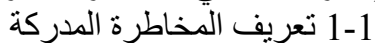

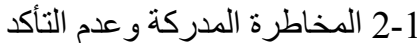
|-1 - 3-1 مكونات المخاطرة المدركة.

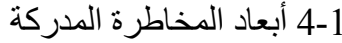

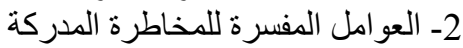

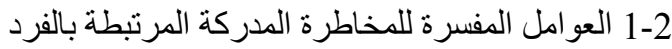

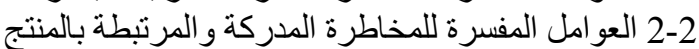

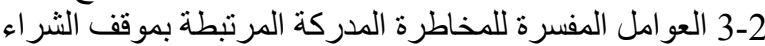

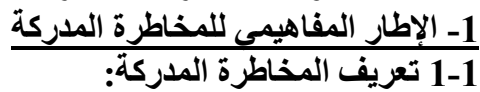

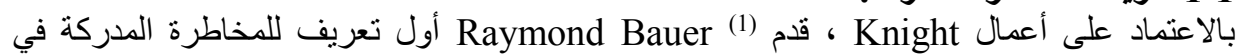

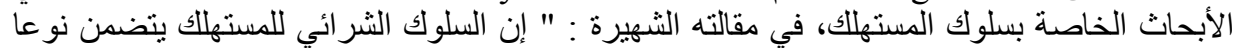

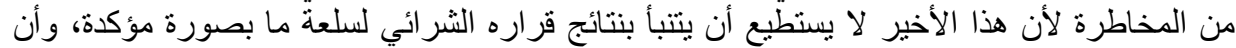

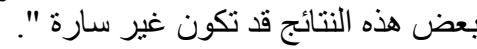

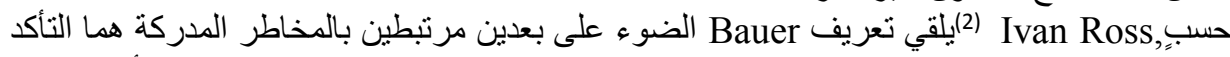

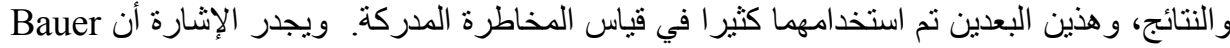




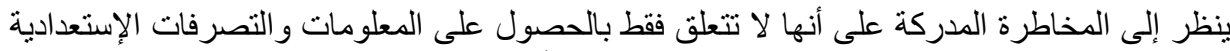

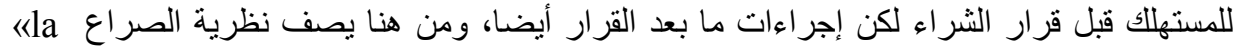
théorie de dissonance»

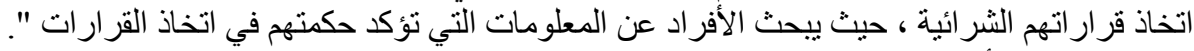

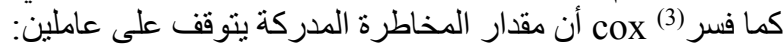

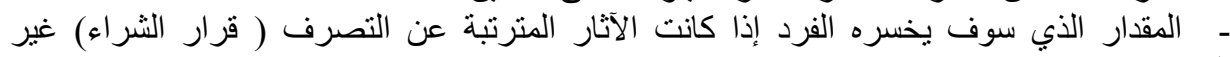

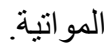
- مشاعر الفرد الذاتية من اليقين أن العو اقب ستكون غير مواتية.

2-1 المخاطرة المدركة و عدم التأكد :

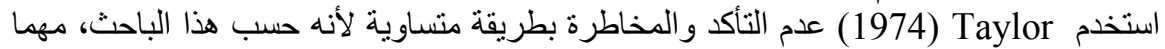

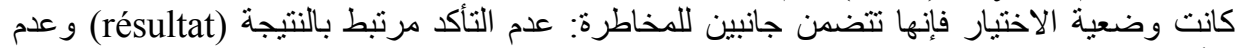

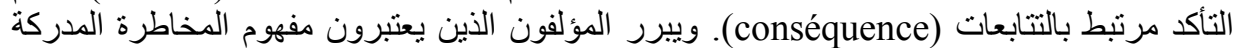

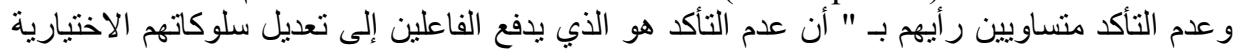

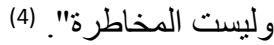
حسب Stone و Gronhaug (1993) (5)"غالبا ما يتم التفرقة بين المخاطرة و عدم التأكد حيث تعرف

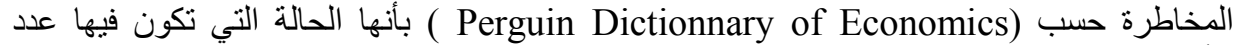

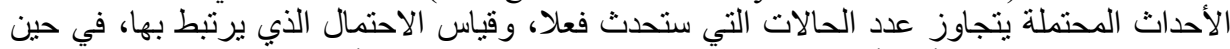

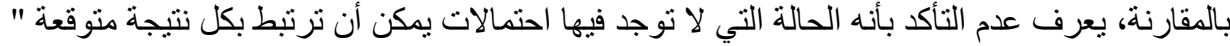

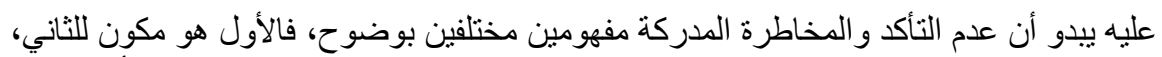

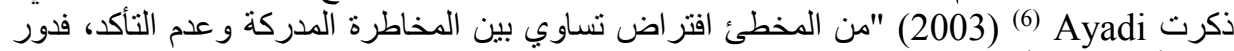

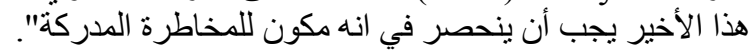

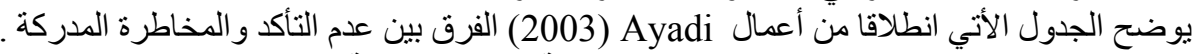
جدول رقم (1): الفرق بين وضعية خطرة ووضعية غير مؤكدة

\begin{tabular}{|c|c|}
\hline Situation risqué وضعية خطرة & وضعية غير مؤكدة (Situation incertaine) \\
\hline كلا من النتائج المحتملة و احتمالاتها معروفة . & 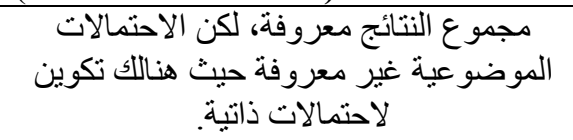 \\
\hline
\end{tabular}

Source : Paul Emmanuel Pichon, Les comportements du consommateur face aux produits alimentaires : Du risque perçu à la confiance, op cit, $\mathrm{p}: 43$.

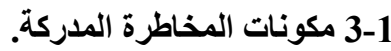

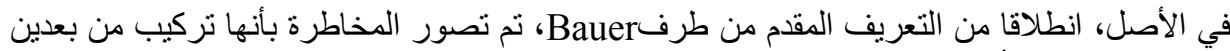

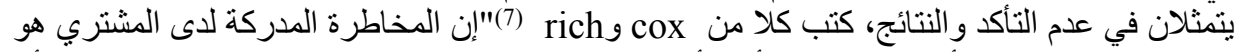

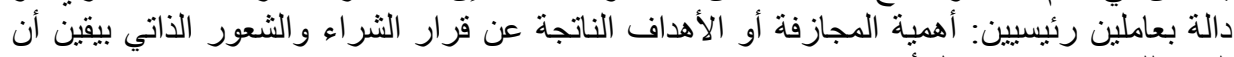

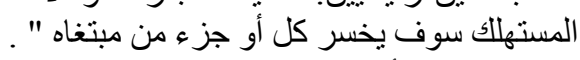
1-3-1

بالنسبة لــ Mallet (2002) (8) مكون عدم التأكد يمكن أن يفهم من حقيقة أن الفرد لا يمكنه تقدير مجموع عو اقب الاختيار الذي قام به بيقين أثناء شراء سلعة أو خدمة، فلا يمكنه إذا سوى تقدير 


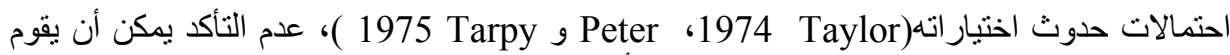

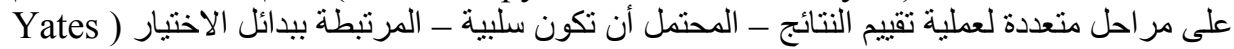

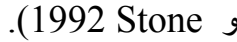

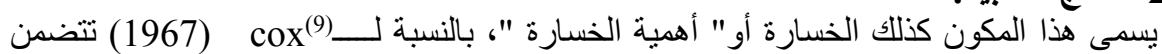

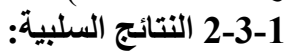

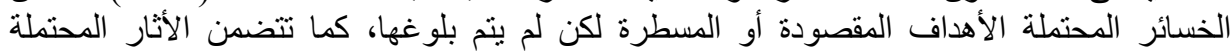

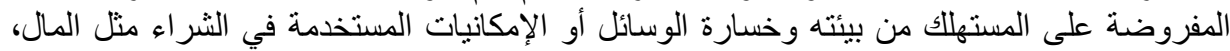

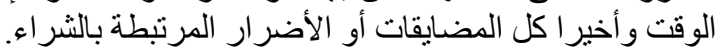
قدم Arndt (1968) مكون ثالث هو مفهوم الأهمية الذي يسمح بتحديد مستوى الاهتمام الذي يمنحه المستهالك للنتائج السلبية .

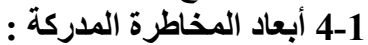

ينظر بعض المؤلفين إلى المخاطرة الددركة في مجلهانها، في حين بعتقد مؤلفون آخرون أن المخاطرة

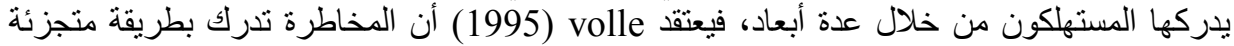

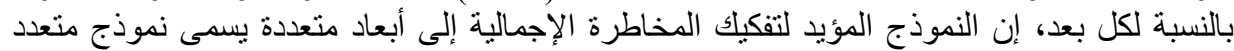

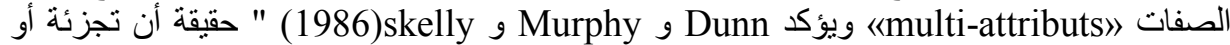
تحليل المخاطرة الدركة إلى أبعاد مختلفة يسمح بتقايم تصور أكثر وضوحا للتركيية الأساسية لمكون

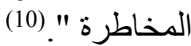

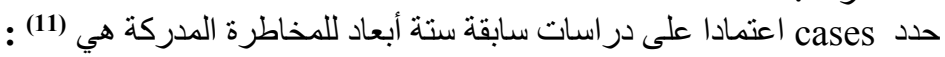

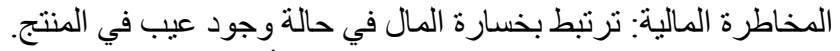

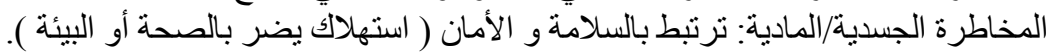

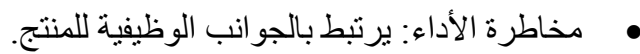

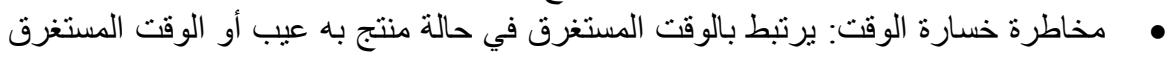

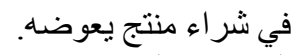

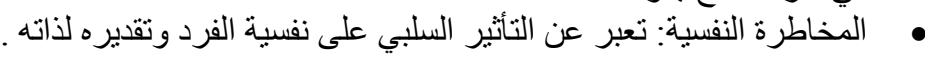

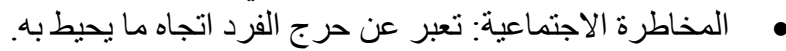

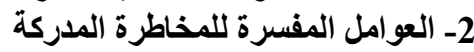

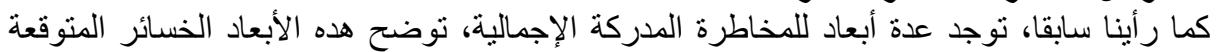

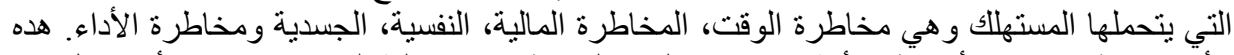

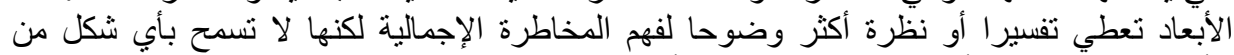

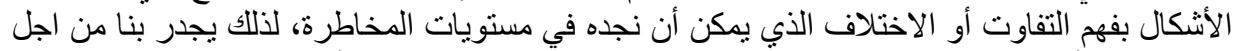

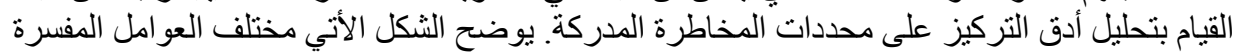
الإدر الك المخاطرة حسب التركين على volle. 


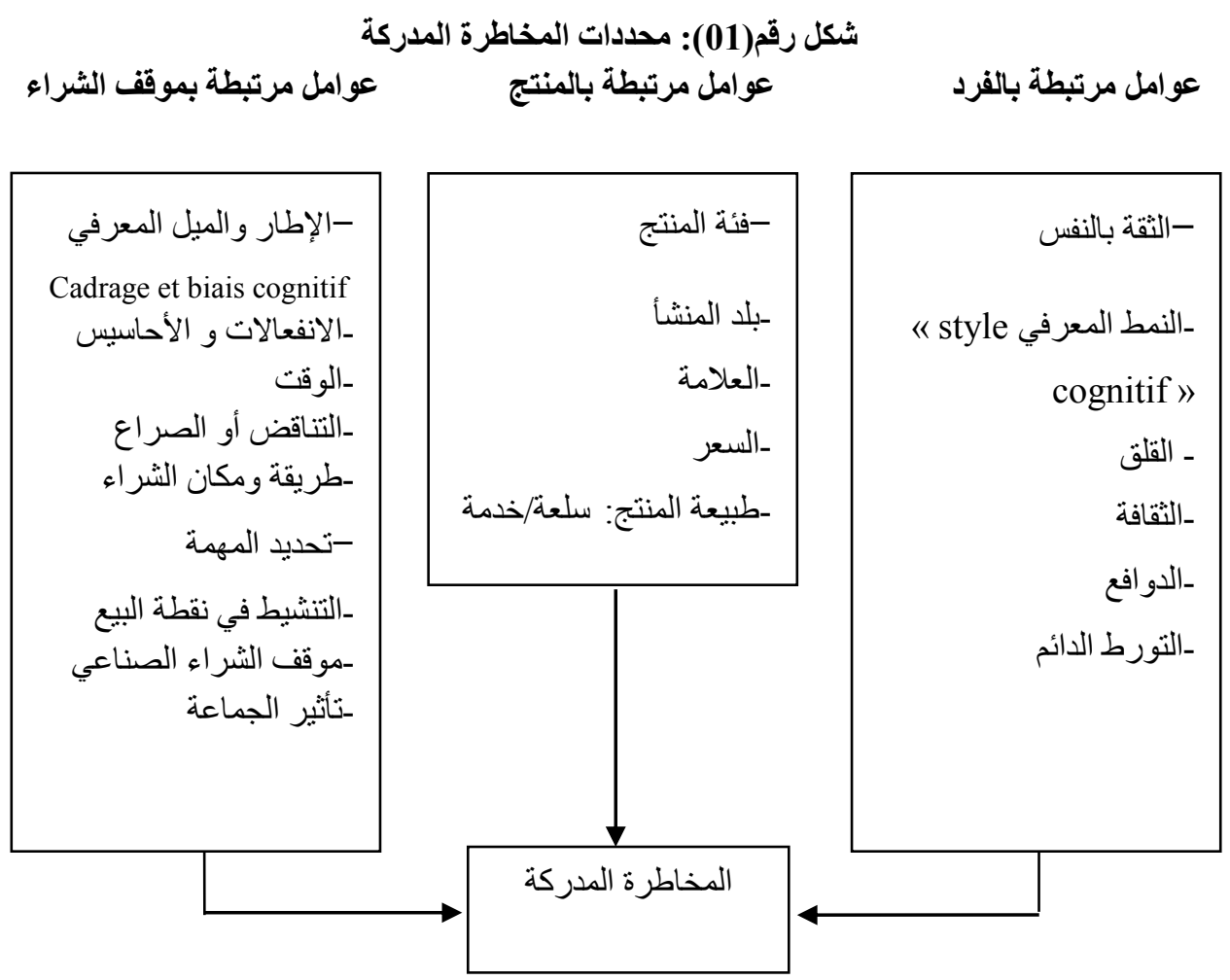

Source : Pierre Volle, le concept de risque perçu en psychologie du consommateur. op cit. P47.

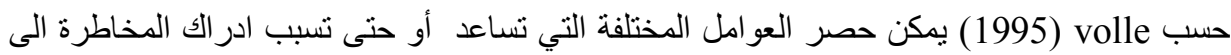

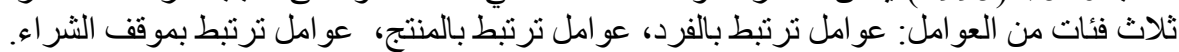

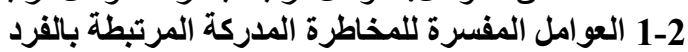

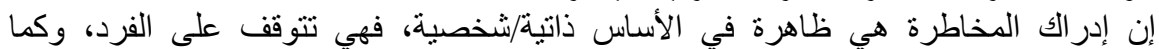

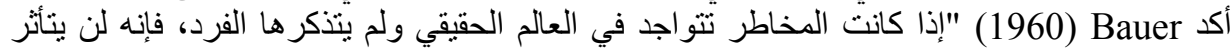

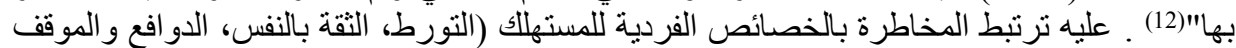

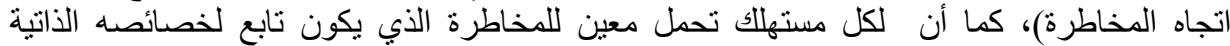

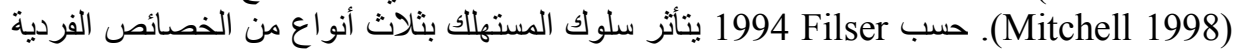

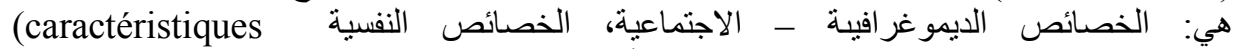
(caractéristiques الخصائص السيكو غر افيبة أو خصائص المخطط النفسية psychologiques) .psycho graphique)

1-1-2-1المتغيرات الايموغرافية الاجتماعية:

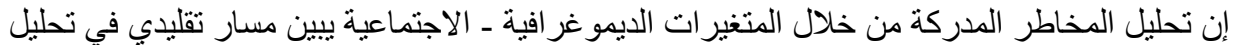

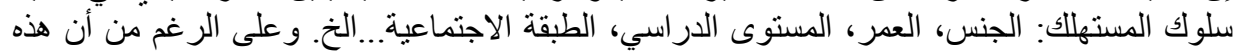

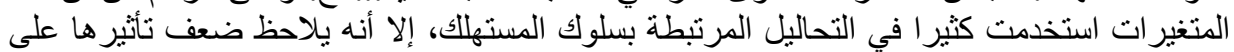

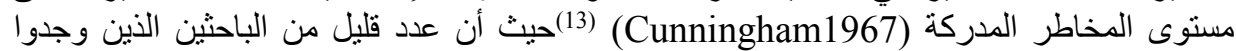


(1985 Miller, 2000 علاقة ذات معنى بين المتغيرات الديمو غر افية_الاجتماعية و إدر الك المخاطرة .Mallet,1995 Volle) : 1-1-1-2

أوضحت دراسة Wogang (1964) Wallach بأن العمر يعتبر متغبر ا مهما ومؤثرا في المخاطرة

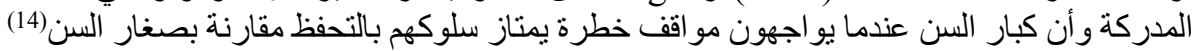

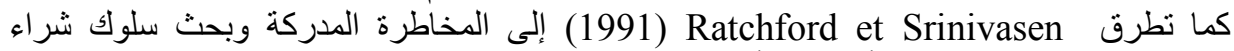

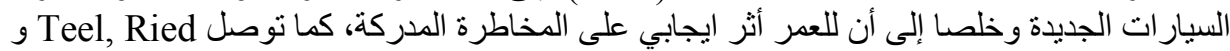
(1980) Vandanberg

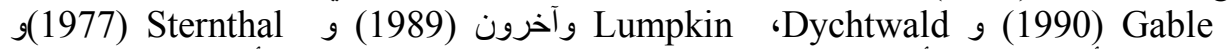
أن كبار السن أكثر حذرا في اتخاذ القرارات مقارنة بالفئات العمرية الأخرى وييحثُن بيقين قبل أي تصرف.15) - (15)

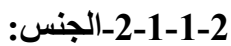

تؤكد النتائج التي توصل إليها-19itchell (1998) أن الرجال لهم ميل للمخاطرة أو المجازفة أكثر من

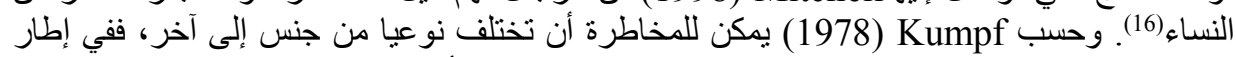

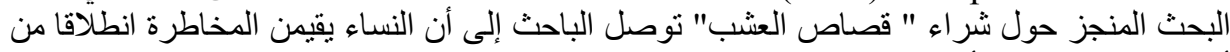

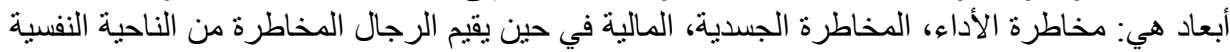
والاجتمأعية. (17)

- 2-1-1-2 الطبقة الاجتماعية:

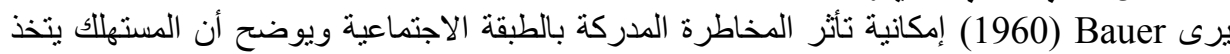

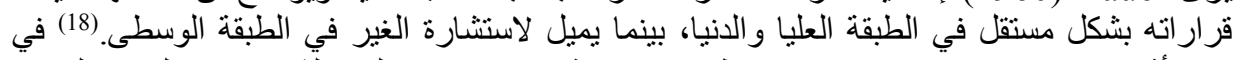

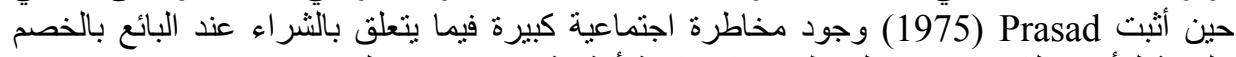

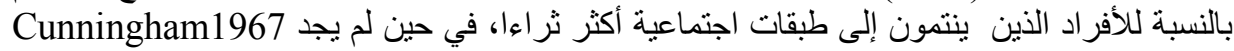

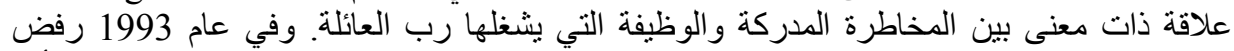
Boustani Mitchell

(les caractéristiques psychologiques) العوامل النفسية (1-2-2

من بين الخصائص النفسية، تقدّم دوافع الفرد ونورطه كمشتري توضيحات مهمة لتفسير مصدر

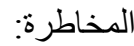

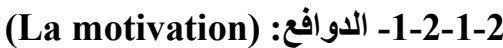

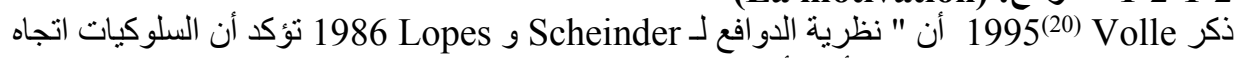

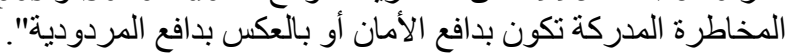

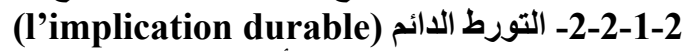
عرف 1981 Bloch التورط بأنه "حالة غير ملاحظة تعكس مستوى الاهتمام، الإثارة و والارتباط

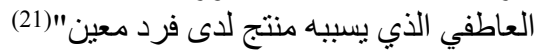

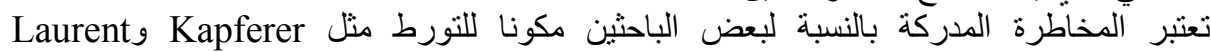

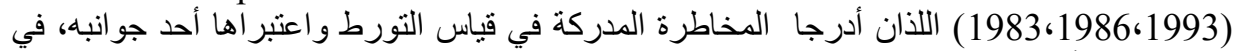

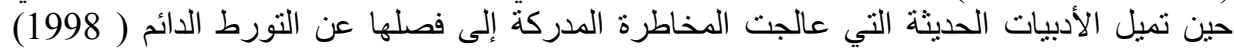
Mitchell

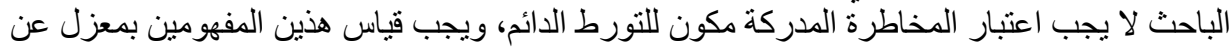
بعضهما البعض. (23) ويوضح الثنكل الأتي العلاقة بين المخاطرة المدركة و التورط: 
شكل رقم(2): التورط الدائم والمخاطرة المدركة

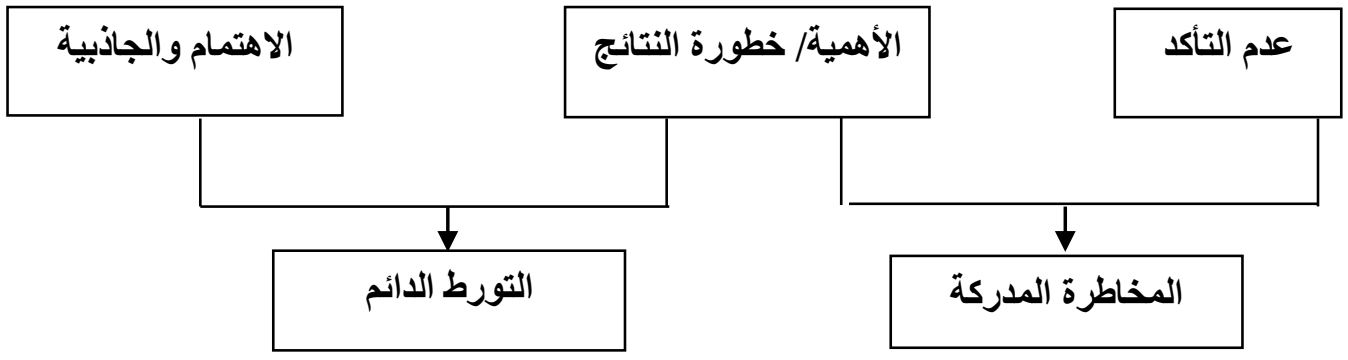

Source: Alain Strazzieri, Mesurer l'implication durable vis -à-vis d'un produit indépendamment du risque perçu, op cit, $\mathrm{p}: 78$.

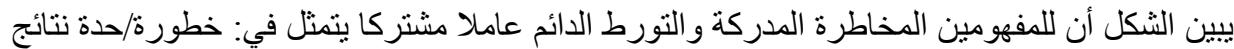

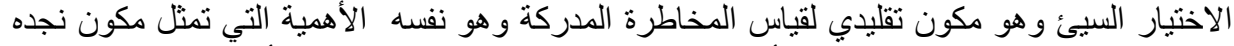

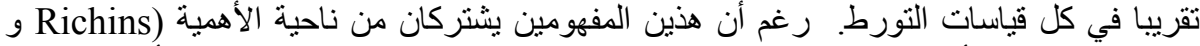
(1983Bloch

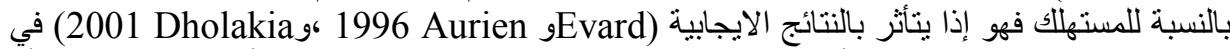
حين تمثل المخاطرة الدركة الأهمية والاحتمال المدركين للنتائج السلبية لثراء أو استهلاك سلعة أو في

أثبت Dholakia (1997) أن مستوى التورط برتبط إيجابا مع المخاطرة المدركة، وأكد (1998)Nantel

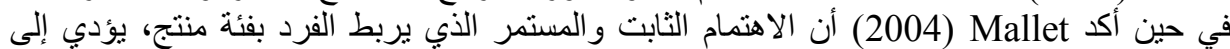

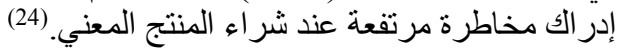

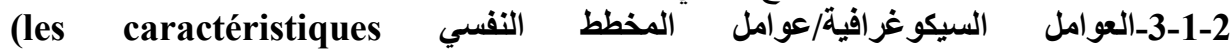
psychographique)

يرتبط هذا النوع من العوامل بسمات شخصية الأفراد، قيمهم ونمط معيشتهم، ويمكن إن يكون لهذه الكئه العوامل تأثير ات متباينة على إدر الك المخاطرة، نذكر منها: النمط المعرفي، الثقة بالنفس، الأحاسيس، القلق و الموقف اتجاه المخاطرة.

(Le style cognitif) النمط المعرفي) 1-3-1-2 بينت النتائج التي توصل إليها (1985)Muller أنه مهما كانت فئة المنتج المعنبة، فان تقييم المخاطرة

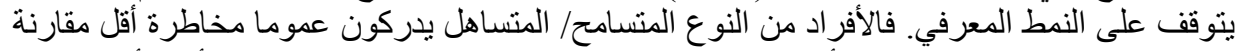

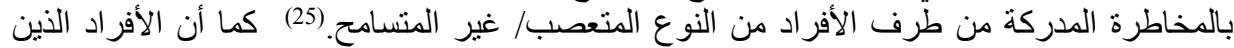

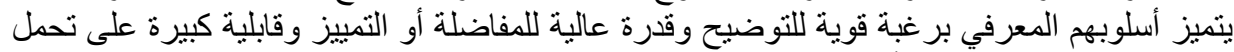

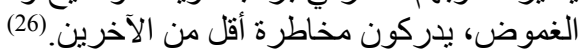

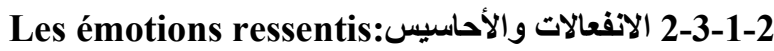

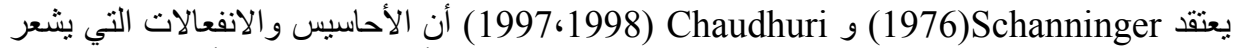
بها الفرد ترتبط سلبا مع المخاطرة المدركة. ويرى Chaudhuri أن الانفعالات والأحاسيس الإيجابية

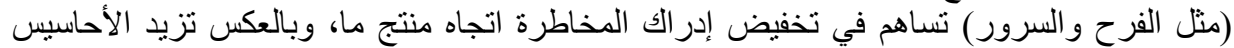
السلبية (الهم، القلق، الغضب، خيبة الأمل) من إدر الك المخاطرة. (27-1)

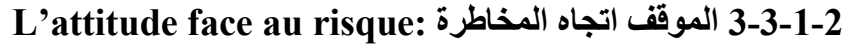




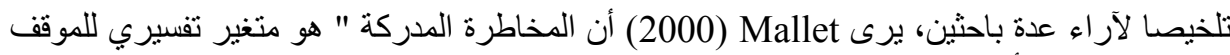

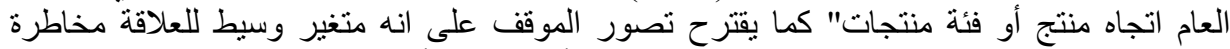

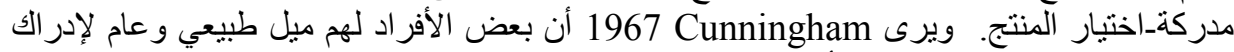

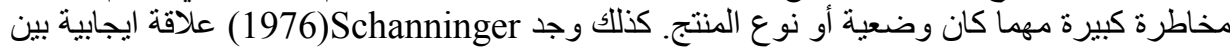

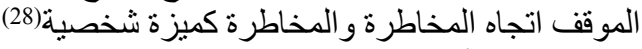

La confiance en soi : 4-3-1-2

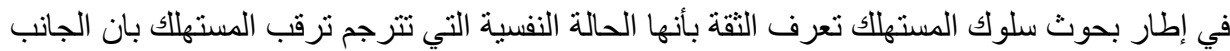

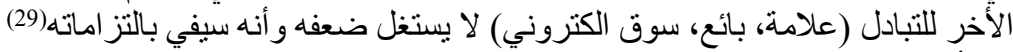

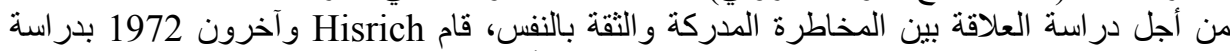

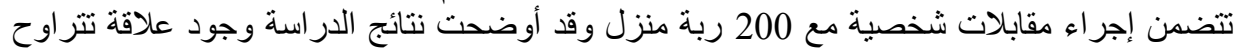
بين ضعيفة إلى معتلة (لكنها ذات دلالة إحصائية) بين المخاطرة والثقة ولثة وبين درجة البحث عن عن

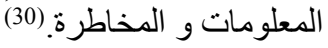

(L’anxiété) 5-3-1-2

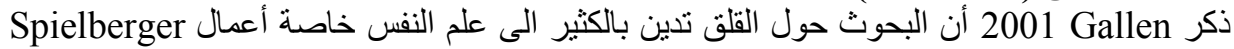
ويتكون القلق من مكونين هما القلق كصفة (L'anxiété-trait) و القلق كحالة (L'anxiété-état).

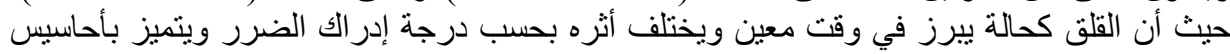

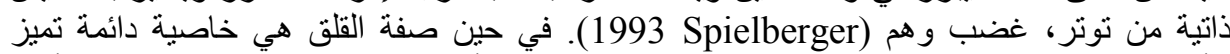
الأفراد وتمثل الميل نحو إدراك حالكات الكات توتر وضغط على أنها وضعيات خطرة ومهددة والتأهب للاتصرف إزاء هذه الوضعيات.

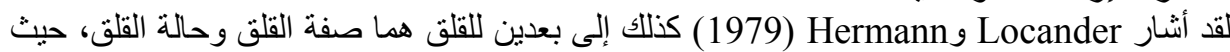

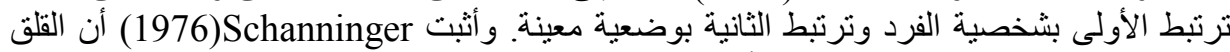

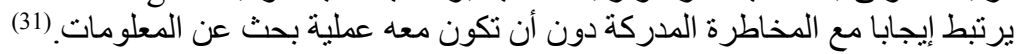

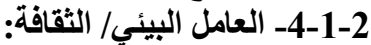

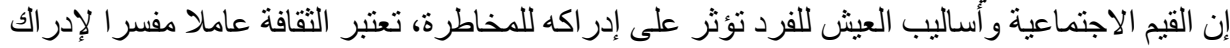

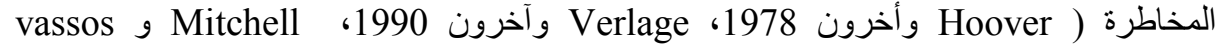
${ }^{(32)}(1997$

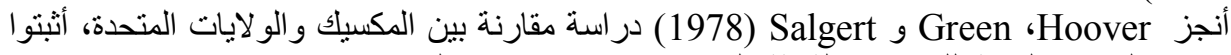

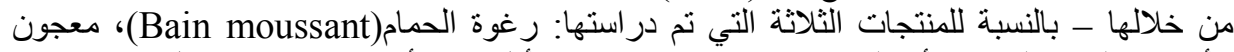

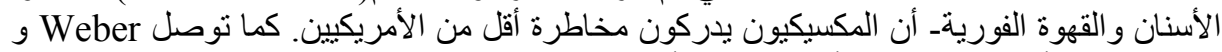
1998Hsee

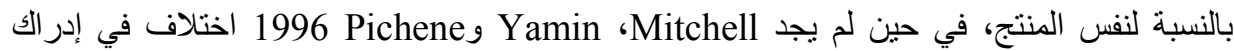

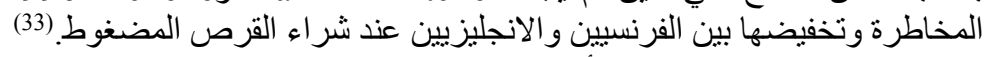

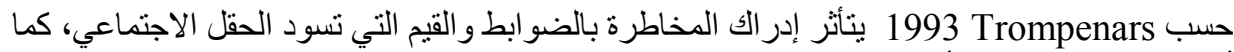
أثبت 1990 Delener أن التوجهات الدينية للفرد نؤثر على مستوى المكائر المخاطرة المدركة لدى المشتري.

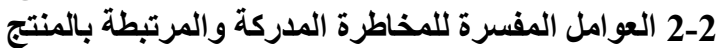

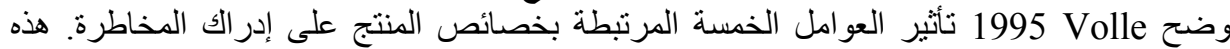

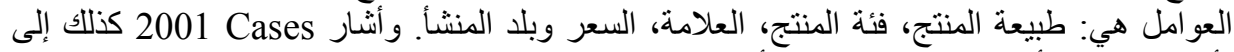

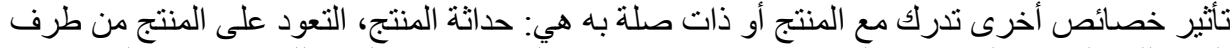

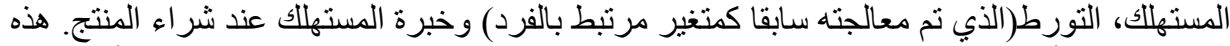

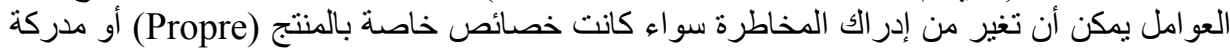
مع المنتج(perçu). 


\section{1-2-2 نوع / طبيعة المنتج(سلعة أو خدمة):}

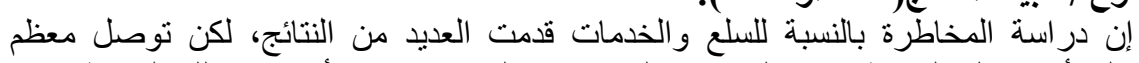

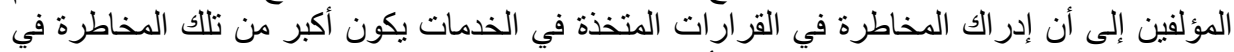

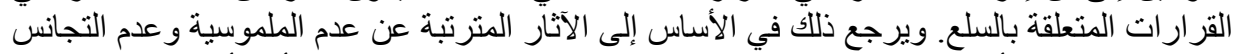

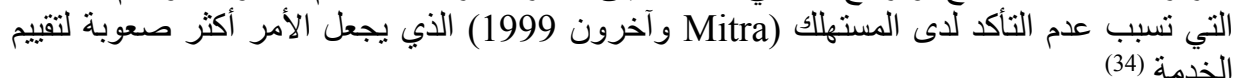

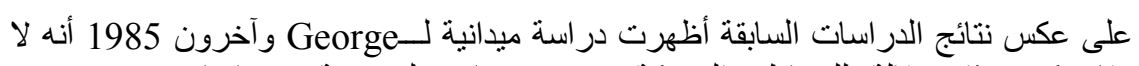

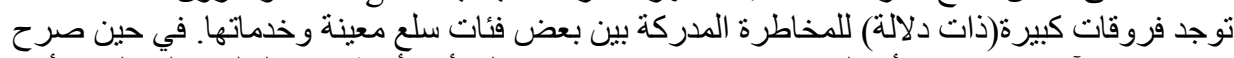
Laroche

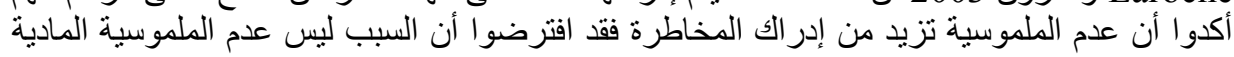

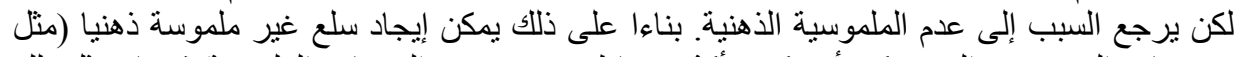

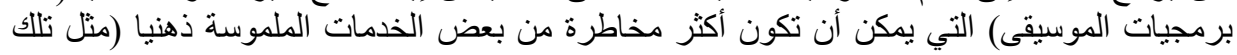

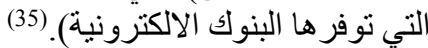

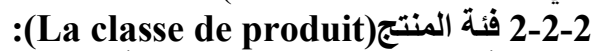

أكد 1967 Gunningham أنه توجد مستويات مخاطرة تختلف بحسب المنتجات المعنية،

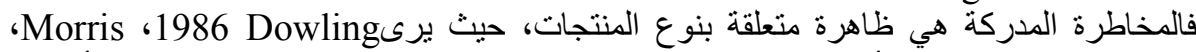
1994 MazisوSwasy

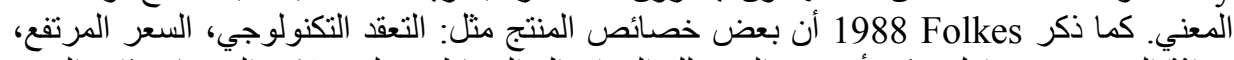

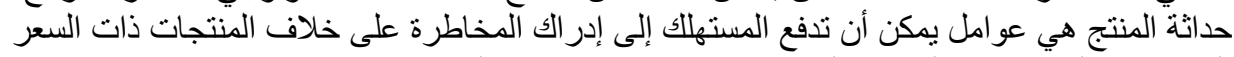

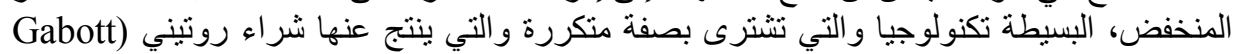
(36).). (1991

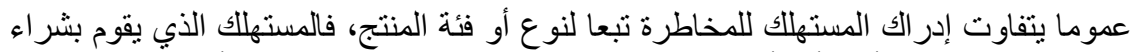

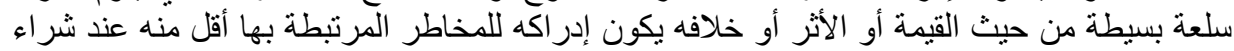

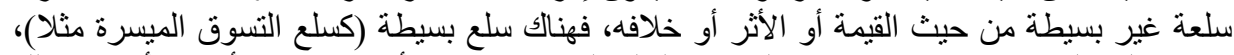

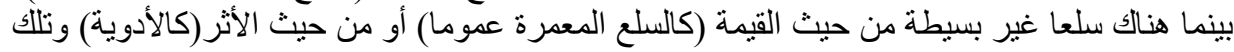

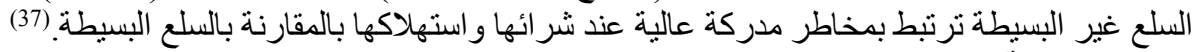

2-3-2-2 - العلامة (La marque):

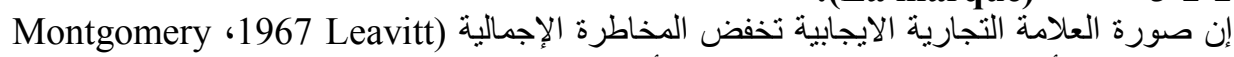

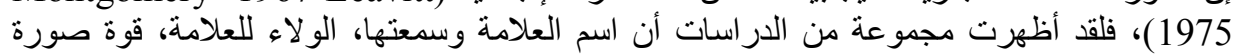

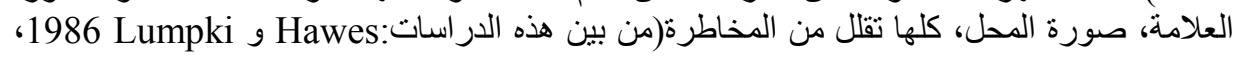
(38)(1971Roseilus إن إعادة شراء علامة ما هو وسيلة تستخدم بشكل كبير من طرف المنام المستهلك لتخفيض المخاطرة (1971Roseilus)

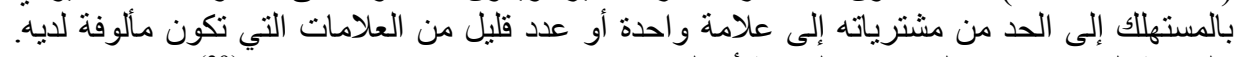

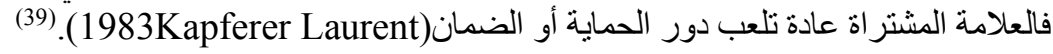

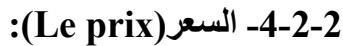

يعتبر السعر متغير المكن أن يؤثر في اتجاهين: في حالة سعر مرتفع يقترن معاه وجود مخاطرة مالية

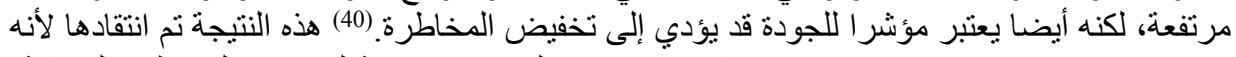

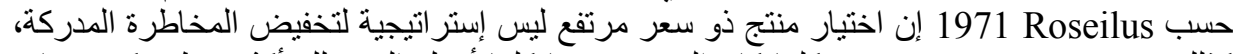

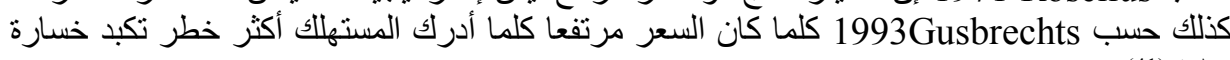


ذكر 1998 Mitchell أن مصدر أو أصل المنتج له دورا مهما في إدرالك المخاطرة. كذلك برهن

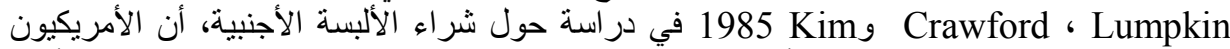

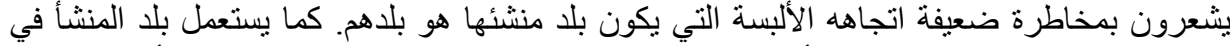

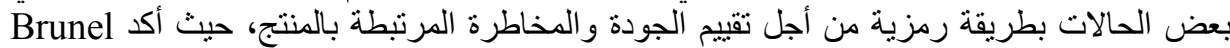

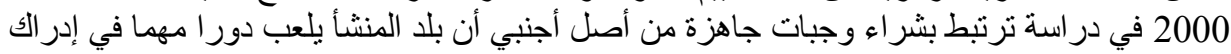

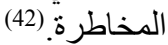

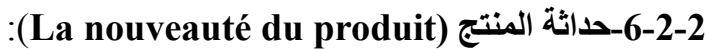
إن تجريب منتج جديد هو مرادف للمجازفة أو المخاطرة بالنسبة للمستهلك، كما ربط كل من

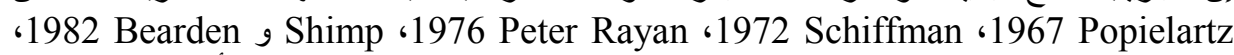

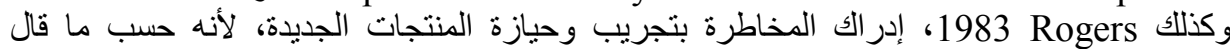
1967 Popielartz مختلفة ". (43)

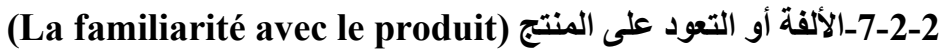

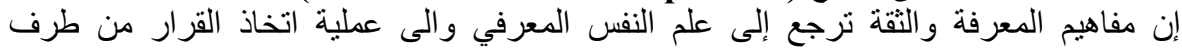

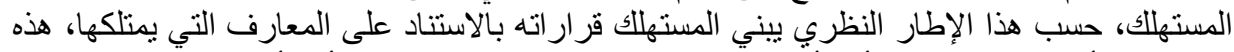

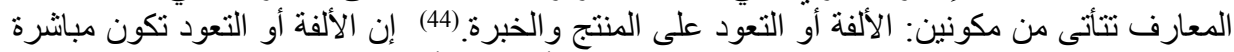

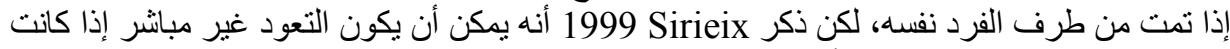
المعلومات تم الحصول عليها من أنثخاص آخرين.

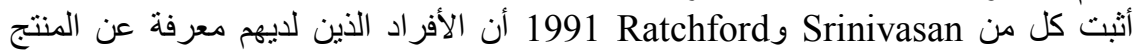

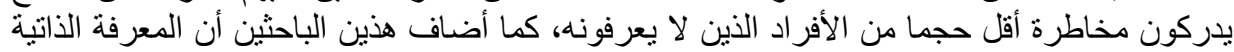

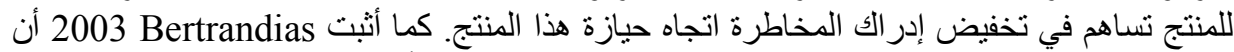

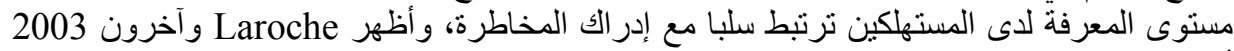

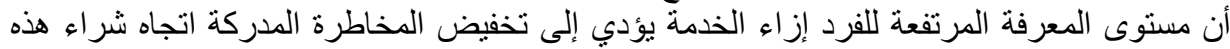

إن الخبرة خبرة المشتري (L'expertise de l'acheteur):

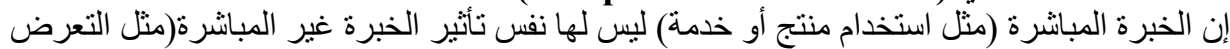

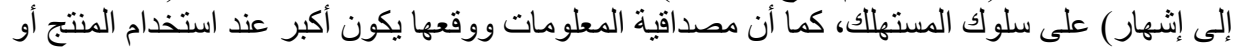

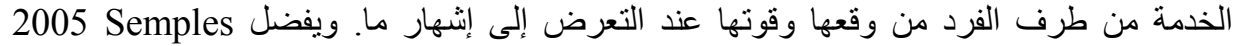

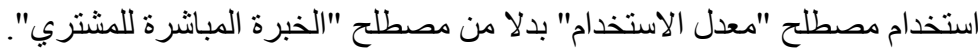

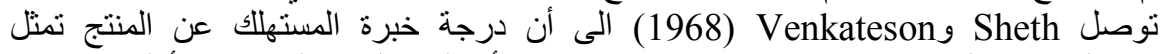
إستر اتيجية لتخفيض المخاطرة. كما بر هن Mallet (2004) أن المستهلكون الذين خاب أملهم في منتج

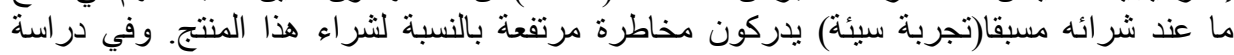

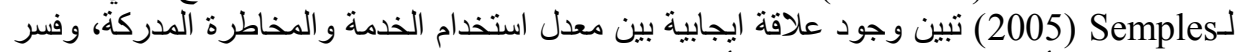
ذللك من حقيقة أن تجربة خدمة ما، يمكن أن تكون سيئة وتؤدي إلى مخاطرة مدركة إضافية في ذهن المستهلك.

3-2 العوامل المفسرة للمخاطرة المدركة المرتبطة بموقف الثراء

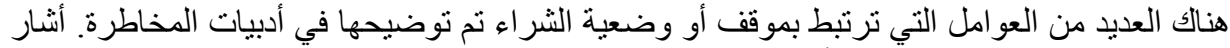
Staeling Dowling (2001) Cases

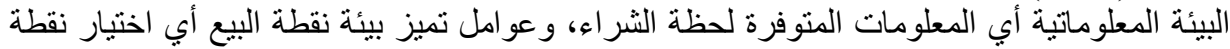
البيع و البيئة المادية و الاجتماعية. 
عليه تقسم العو امل المفسرة لإدراك المخاطرة المرتبطة بموقف الثر اء إلى: ـ عو امل بيئة نقطة البيع: تضم الوقت، المز اج، اختيار طريقة ومكان الثراء الئر وأيضا التنشيط داخل نقطة

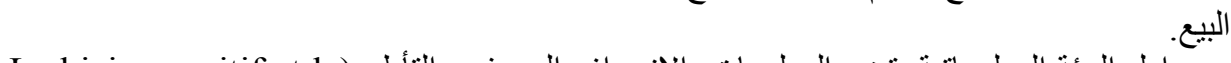
- عو امل البيئة المعلوماتية: تضم المعلومات، الانحر اف المعرفي والتأطير(Ce biais cognitif et le (cadrage

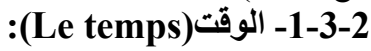
يعتبر الوقت عاملا مفسر الإدر الك المخاطرة، فقجوة الوقت بين القرار(استهلاكاك أو شر اء) ونتائج القرار

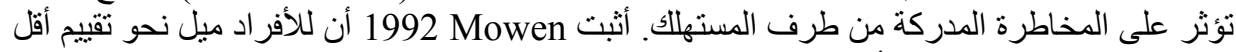

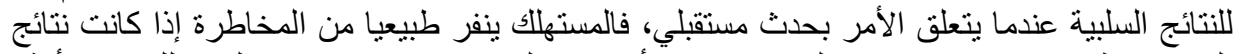

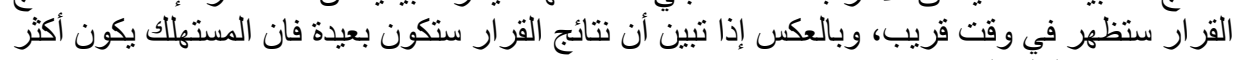

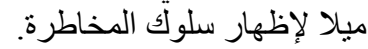

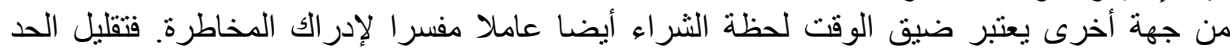

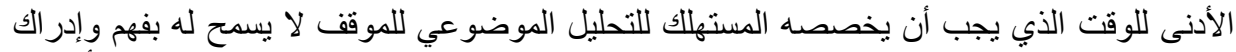

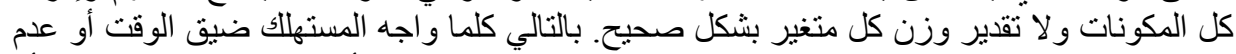

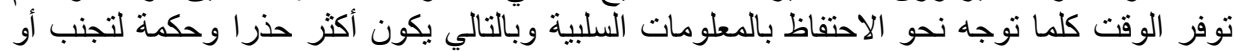

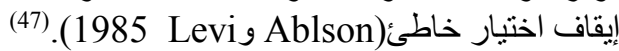

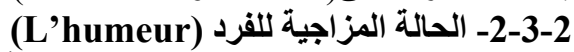

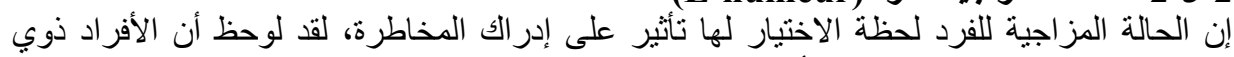

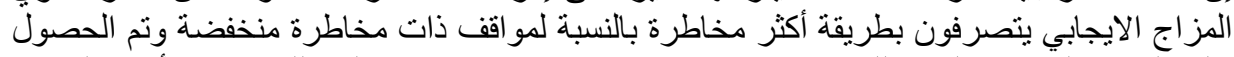

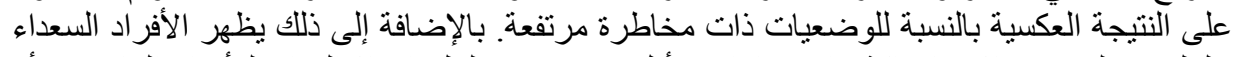

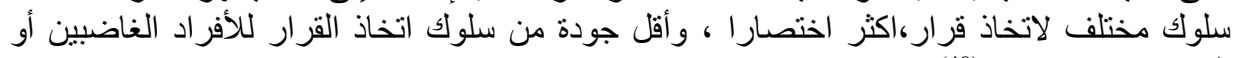

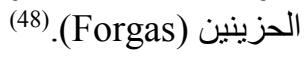

-3-3-2 - طريقة ومكان الثراء.

تدرك بعض طرق طرئل الثراء الثلى أنها أكثر مخاطرة من طرق شراء أخرى، خاصة الثراء عن طريق

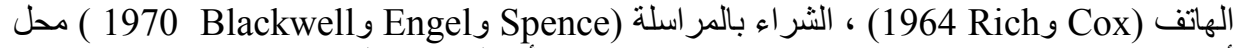

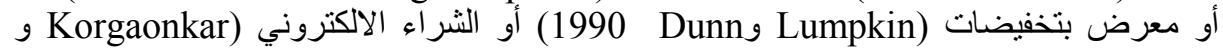
1989 Moschis

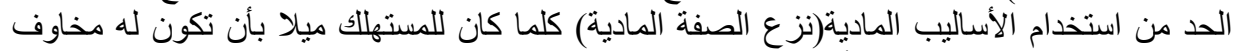

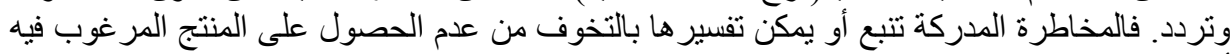

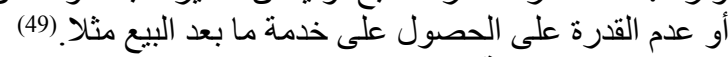

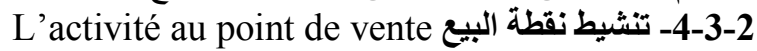
من بين العوامل الموقفية المرتبطة ببيئة نقطة البيع بيعتبر التنشيط في نقطة البيع، الأنشطة الترويجية وتأثير الإثشار في اختيار علامة معينة، أنشطة تستخدم في نقطة البيع تسمح بتفسير ادر الك المخاطرة

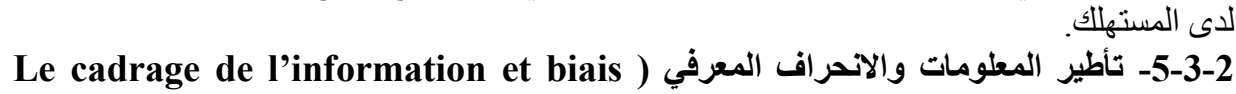
(cognitive

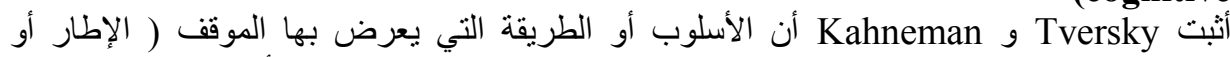

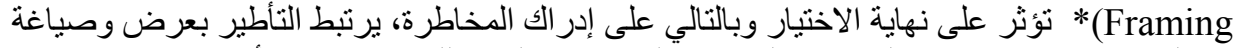

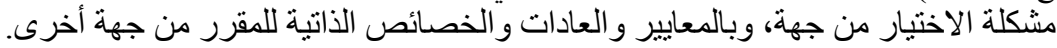




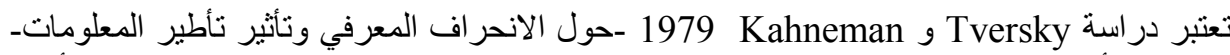

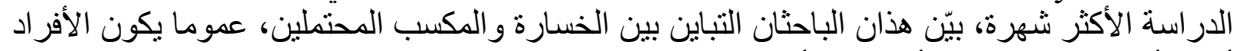

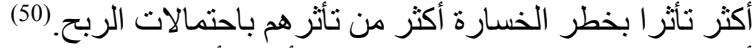

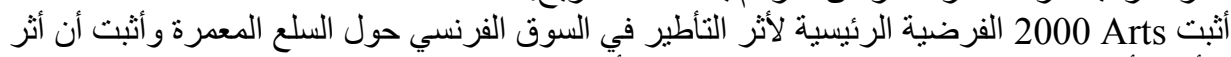

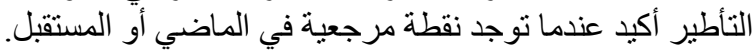

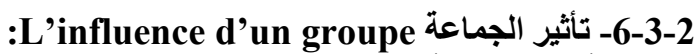

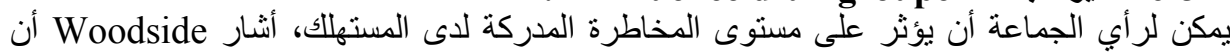

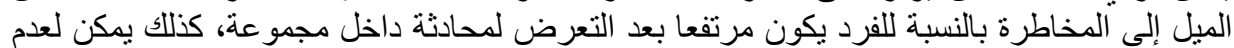

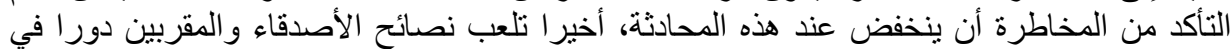

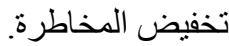

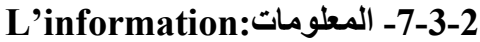

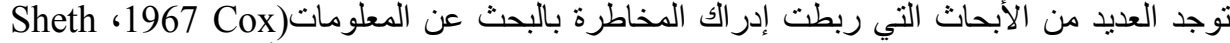

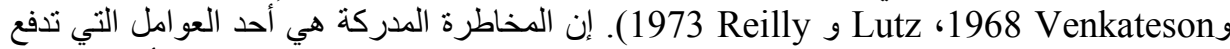

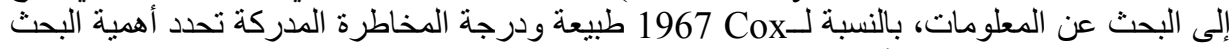

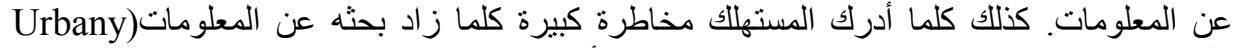
وآخرون 1989) وكان الوقت المخصص اللبحث أكبر وكانت المعلومات المجمعة كثيرة(كheth .1991 Gabott ، 1968Venkateson, يعتقد 1973 أن الدخاطرة الددركة تئثر على تقيبم قيمة مصدر

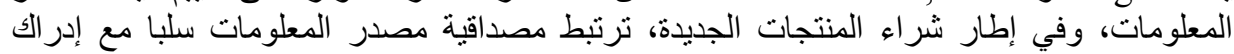

المخاطرة(1982Bearden و (19).

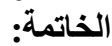

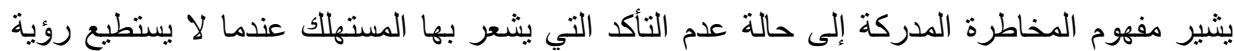

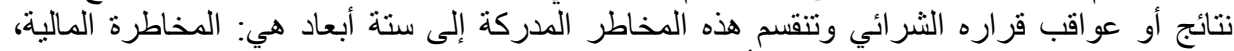

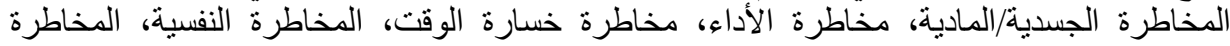

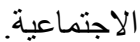

ومن خلال ما سبق نؤكد الفرضيات التي طرحت في بداية البحث حيث يرجع الثعبور بالمخاطرة

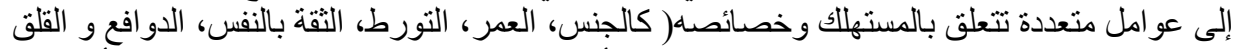

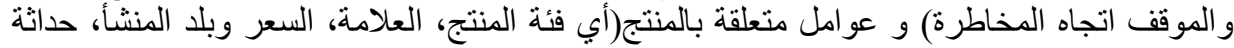

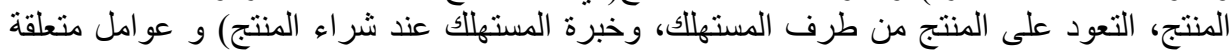

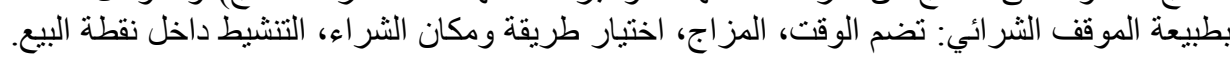
بالإضافة إلى المعلومات، الانحر اف المعرفي والإطار.

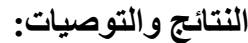
من خلال البحث تم التوصل الى النتائج الآتية :

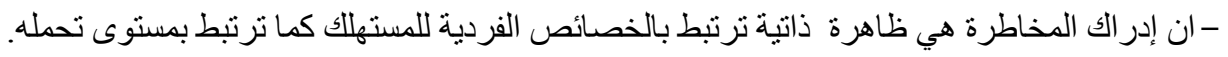

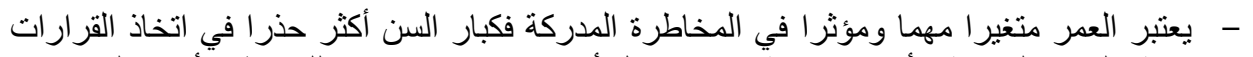

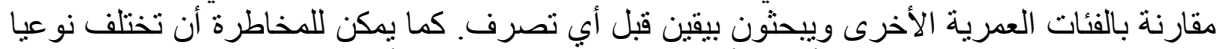

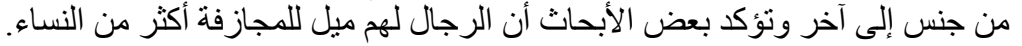

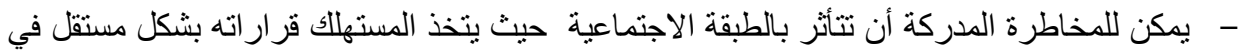
الطبقة العليا و الدنيا، بينما يميل لاستثارة الغير في الطبقة الوسطى. 
- - أثبت بعض الباحثين أن مستوى التورط يرتبط إيجابا مع المخاطرة المدركة، في حين أكد آخرون أن

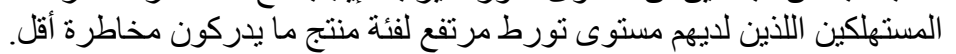

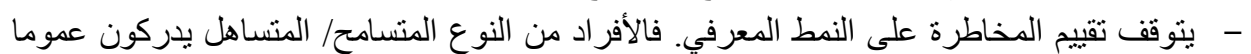

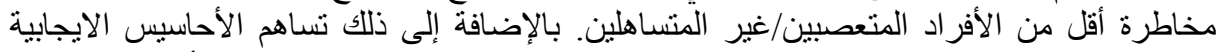

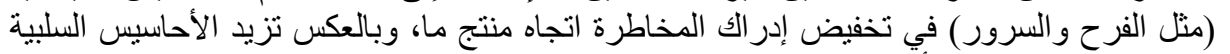
(القلق، الغضب، خيبة الأمل) من إدر الك الدخاطرة.

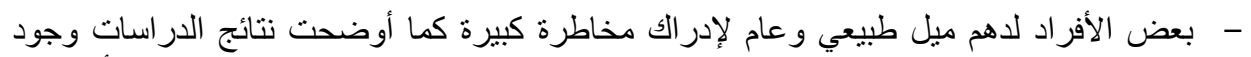

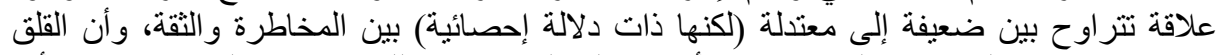

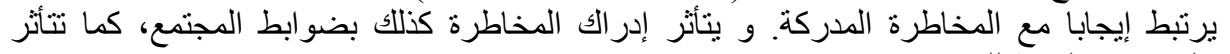
بالتوجهات الدينية للمشتري.

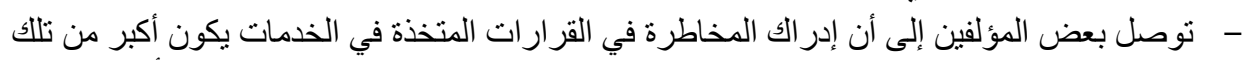

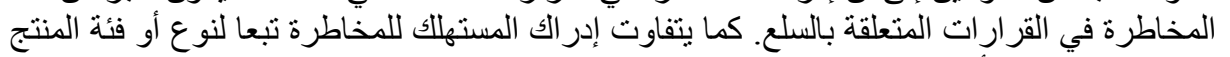

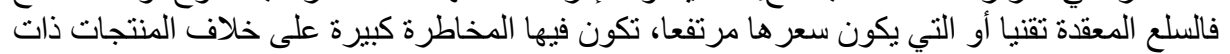

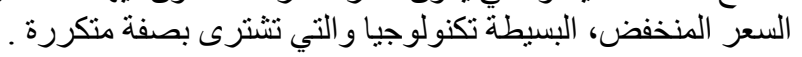

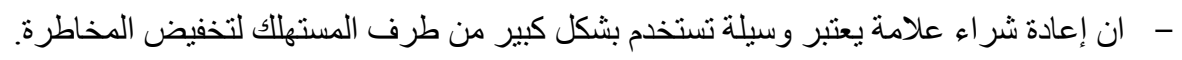

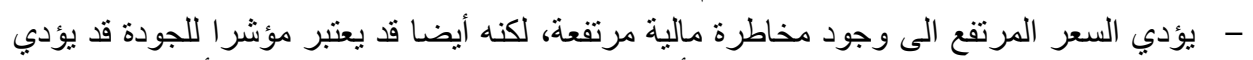

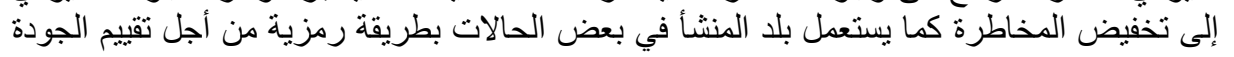

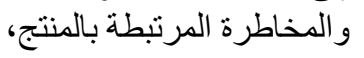

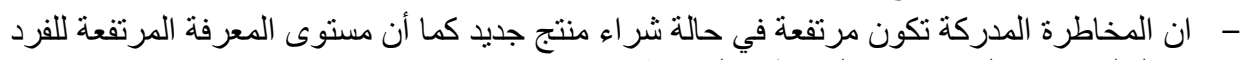

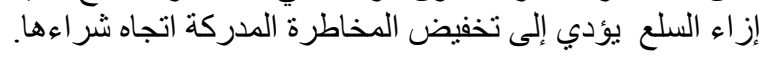

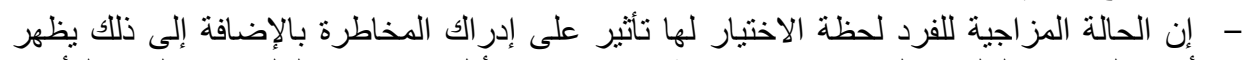

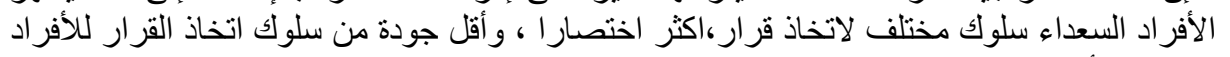
الغاضبين أو الحزينين.

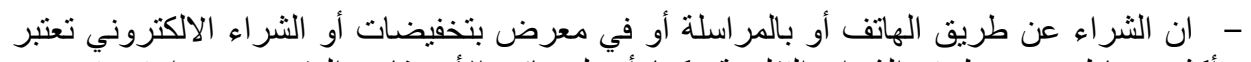

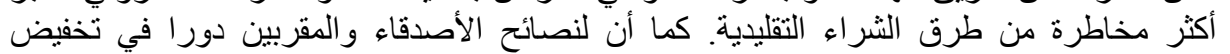

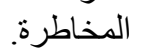

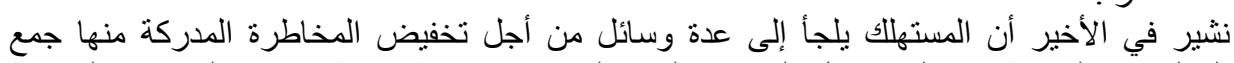

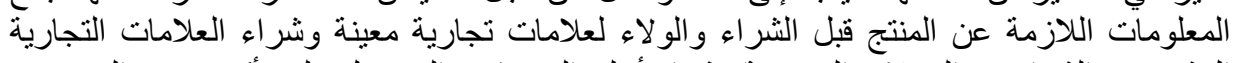

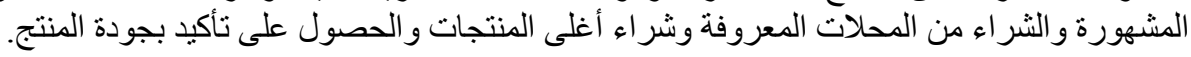

1-Robert N Stone, Kjell Gronhaug, Perceived risk: further considerations MBC University press, 1993 , p:39.

2- Ivan Ross, Perceived risk and consumer behavior: A critical review, Advances in consumer research, Vol2, 2 issue, 1975, p: 1.

3- Donald F Cox, Stuart U Rich, Perceived risk and consumer decisionmaking, the case of telephone shopping, Journal of marketing research, Vol1,N4, Nov 1964, p:33

4- Ibid, pp :42,43. 
5- Robert N Stone, Kjell Gronhaug, Perceived risk: further considerations, op cit, pp:40,41.

6-Paul Emmanuel Pichon, Les comportements du consommateur face aux produits alimentaires : Du risque perçu à la confiance, Editions universitaires européennes, Allemagne, 2010, p: 43.

7- Olivier Brunel, Perception et réduction du risqué alimentaire, op cit, p :67.

8- Samira Zine- Danguir, Saloua Touil, Impact du contexte du rôle sur le risque perçu, Editions universitaires européennes, Allemagne, 2010, p : 10.

9- Pierre Volle, Le concept de risque perçu en psychologie du consommateur : antécédents et statut théorique, Recherche et Application en marketing, Vol 10, $\mathrm{N} 1,1995, \mathrm{p}: 40$.

10-Anne-Sophie Cases, les effets de l'internet sur le comportement de réduction du risque des consommateurs, 5éme journée de recherche en marketing de Bourgogne, $\mathrm{p}: 70$.

11 - ibid, $\mathrm{p}: 71$.

12- Jean - Louis Moulins, risque perçu et fidélité à la marque : une analyse exploratoire, revue française du marketing, octobre 2004, N199, P89

13-Loïck Menveille, Analyse du risque perçu chez le cyberconsommateur français et canadien, dans le processus d'achat de services : une application au tourisme médical, thèse de doctorat en science de gestion, université de Nice Sophia-Antipolis, 2001, P122

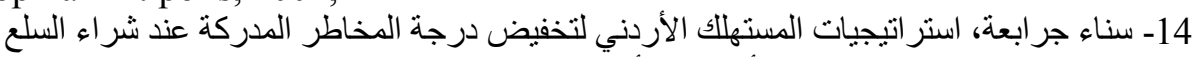

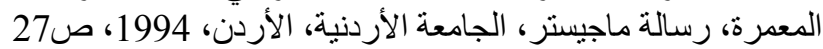

15- Piter Simcock, Lynn Sudbury, Gillian Wright, age, Perceived risk and satisfaction in consumer decision making: a review and extension, Journal of marketing Management, west burn publishes, 2006,22, P357

16- Paul Emmanuel Pichon, Les comportements du consommateur face aux produits alimentaires : Du risque perçu à la confiance, op cit, $p$ :62

17- Olivier Brunel, Perception et réduction du risqué alimentaire, op cit, p :99.

18- سناء جر ابعة، استر اتيجيات المستهلاك الأردني لتخفيض درجة المخاطر المدركة عند شر اء السلع

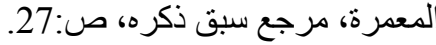

19- Olivier Brunel, Perception et réduction du risqué alimentaire, op cit, p :99.

20- Pierre Volle, Le concept de risque perçu en psychologie du consommateur, op cit, $\mathrm{p}: 47$

21-Alain Strazzieri, Mesurer l'implication durable vis -à-vis d'un produit indépendamment du risque perçu, recherche et application en marketing, vol9, n1, sage publication-ltd,1994,p :84.

22- Idir Ouzaka, implication et risque perçu : ambigüité conceptuelle ou problème de mesure, institut d'administration des entreprises, voir le site web : www.cergam.org/fileadmin/files/cerog/wp/607.pdf

23- Alain Strazzieri, Mesurer l'implication durable vis -à-vis d'un produit indépendamment du risque perçu, op cit, $\mathrm{p}: 83$. 
24-Samira Zine- Danguir, Saloua Touil, Impact du contexte du rôle sur le risque perçu, op cit, $\mathrm{p}: 40$

25- Jean - Louis Moulins, risque perçu et fidélité à la marque, op cit, p :90.

26- Philippe Mouillot, Le comportement du consommateur, Gualino éditeur, Paris, 2007, p :90.

27-Paul-Emmanuel Pichon, Les comportements du consommateur face aux produits alimentaires : du risque perçu à la confiance, op cit, $\mathrm{p}: 66$

28-Pierre Volle, Le concept de risque perçu en psychologie du consommateur, op cit, $\mathrm{p}: 47$

29-Ines Chouk et Jean Perrien, les facteurs expliquant la confiance du consommateur lors d'achat sur un site marchand, Décision marketing, n35, juillet/ septembre 2004, p : 76.

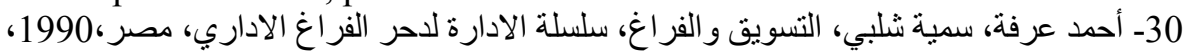

31- Pierre Volle, Le concept de risque perçu en psychologie du consommateur, op cit, $\mathrm{p}: 47$

32-Loïck Menveille, Analyse du risque perçu chez le cyberconsommateur français et canadien, dans le processus d'achat de services, op cit, $\mathrm{p}: 123$

33- Olivier Brunel, Perception et réduction du risqué alimentaire, op cit, $\mathrm{p}: 100$.

34-Pérez-Cabanéro, Carmen, Perceived risk in good and service purchases,

Esic market, N129,April 2008, p:185.

35- Ibid , pp: 185-186.

36- Olivier Brunel, Perception et réduction du risqué alimentaire, op cit, pp:94,95.

$$
\text { 37- أحمد عرفة، سمية شلبي، التسويق و الفراغ، مرجع سبق ذكره، ص: } 146 .
$$

38- Mariné Aghekyan, The role of product brand image and online store image on perceived risks, and online purchase intentions, Doctorate on philosophy,

Auburn university, Alabana, 2009, p:36.

39- Jean-Louis Moulins, Risque perçu et fidélité à la marque, op cit, $\mathrm{p}: 91$.

40- Philippe Mouillot, Le comportement du consommateur, op cit, p :36.

41- Loïck Menveille, Analyse du risque perçu chez le cyberconsommateur français et canadien, dans le processus d'achat de services, op cit, p:124.

42- Olivier Brunel, Perception et réduction du risqué alimentaire, op cit, p :97

43-Paul-Emmanuel Pichon, Les comportements du consommateur face aux produits alimentaires : du risque perçu à la confiance, op cit, $\mathrm{p} 72$

44- Patrick Longuet, Le consommateur et le risque alimentaire vers un modèle intégrateur d'équilibre, doctorat en sciences de gestion, université de Nice Sophia-Antipolis, 2008, p :168.

45- Samira Zine- Danguir, Saloua Touil, Impact du contexte du rôle sur le risque perçu, op cit, $\mathrm{p}: 40$.

46-Samira Zine- Danguir, Saloua Touil, Impact du contexte du rôle sur le risque perçu, op cit, PP :41-42 
47-Loick Menveille, Analyse du risque perçu chez le cyberconsommateur français et canadien, dans le processus d'achat de services, op cit, p:125.

48- Pierre Volle, Le concept de risque perçu en psychologie du consommateur, op cit, $\mathrm{p}: 48$.

49-Loïck Menveille, Analyse du risque perçu chez le cyberconsommateur français et canadien, dans le processus d'achat de services, op cit, p:125.

50-Patrick Longuet, Le consommateur et le risque alimentaire vers un modèle intégrateur d'équilibre, op cit , $\mathrm{p}: 169$. 